\title{
Humic acid as a model for natural organic matter (NOM) in the removal of odorants from water by cyclodextrin polyurethanes
}

\author{
BB Mamba*, RW Krause, TJ Malefetse, SP Sithole and TI Nkambule \\ Department of Chemical Technology, University of Johannesburg, PO Box 17011, Johannesburg, South Africa
}

\begin{abstract}
Current practices in some water-treatment facilities have reported that natural organic matter (NOM) blocks the adsorption sites of activated carbon resulting in lower geosmin and 2-methylisoborneol (2-MIB) removal. Humic acid has been reported to compete with geosmin and 2-MIB removal in the same way. The removal of odour chemicals such as geosmin and 2-MIB is important for potable-water treatment by water supply companies and municipalities. We have previously demonstrated that cyclodextrin polyurethanes are capable of removing a number of organic pollutants from water, but are not able to reduce the levels of NOM significantly. We wished to determine if the polymers would selectively remove geosmin and 2-MIB, despite the presence of NOM. Humic acid was chosen as a model for NOM since NOM constitutes about $70 \%$ of humic acid. Results obtained from this study indicate that the presence of humic acids at different concentrations could not affect the removal of geosmin and 2-MIB when cyclodextrin polymers were used since $90 \%$ removal was achieved. However the UV-Vis analysis showed a low removal of humic acids ( 3 to $20 \%$ ).
\end{abstract}

Keywords: cyclodextrin polymers, geosmin, 2-methylisoborneol (2-MIB), humic acids

\section{Introduction}

Geosmin and 2-methylisoborneol (2-MIB) are organic compounds that cause bad taste and odour to drinking water. Geosmin and 2-MIB are detectable by the human nose even at 10 $\mathrm{ng} / \ell$ levels. Therefore highly effective treatment methods are required to remove these compounds to low concentration levels (Hepplewhite et al., 2004).

Natural organic matter (NOM) occurs in all natural water sources when animal and plant materials break down. The main NOM component is attributed to humic substances. Humic substances can be divided into three groups depending on the method of isolation from the original substance. These are fulvic acid, humic acid (HA) and humin. Humic substances adversely affect the quality of drinking water since they impart colour and serve as precursors for the formation of chlorinated compounds. They also have complexing properties that include association with toxic elements and micro-pollutants (De Wuilloud et al., 2003).

Activated carbon is currently used in the adsorption of geosmin and 2-MIB. It has, however, been noted that the removal of micro-organic compounds by activated carbon is not reliable, including geosmin and 2-MIB, particularly at low concentrations. This reduced performance can be attributed to the presence of NOM which is usually found in drinking water at concentration levels of between 2 and $15 \mathrm{mg} / \ell$ (Hepplewhite et al., 2004). NOM commonly exists in water at more elevated concentration levels $(\mathrm{mg} / \ell)$ than geosmin and 2-MIB

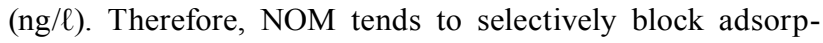
tion sites on activated carbon (Tennat, 2004). NOM effects on micro-pollutants adsorption capacity are more severe for activated carbons that primarily possess small micropores

\footnotetext{
* To whom all correspondence should be addressed.

용 +2711 559 6516; fax: +2711 5596425 ; e-mail: bmamba@uj.ac.za

Received 1 August 2008; accepted in revised form 1 December 2008
}

( $<10 \AA$ in width). For activated carbon that has a broader pore size distribution that includes larger micropores and small mesopores the effect is less pronounced (Quinlivan et al., 2005). This NOM effect may consequently render the activated carbon ineffective in the removal of the odorous compounds. NOM, in other words, compromises the adsorption efficiency of activated carbon significantly resulting in high costs in water treatment (Newcombe et al., 2002). Also, activated carbon loses its adsorption effectiveness once saturated with moisture from air and this causes the adsorbed pollutants to leach out ( $\mathrm{Li}$ and $\mathrm{Ma}, 2000$ ). It has been shown that interaction of water and carbon-oxygen complexes can influence activated carbon adsorption ( $\mathrm{Li}$ et al., 2002).

The synthesis and application of cyclodextrins in the removal of geosmin and 2-MIB has been extensively investigated but to date the effects of NOM on the adsorption process have not been examined. These polymers have been tested in the removal of geosmin and 2-MIB present in water at $\mathrm{ng} / \ell$ from synthetic solutions and real water systems and were found to be effective (Mhlanga et al., 2007; Mamba et al., 2007).

Therefore, the aim of this study was to apply water-insoluble cyclodextrin polyurethanes in the removal of humic acid, geosmin and 2-MIB from synthetically prepared water samples. In particular, the specific objective was to determine whether geosmin and 2-MIB would be removed by the cyclodextrin polymers in the presence of humic acid.

\section{Experimental}

Extraction techniques, gas chromatography-mass spectrometry (GC-MS) analysis of water samples and evaluation of the solid phase micro-extraction (SPME) technique used in this study have been previously reported (Mamba et al., 2007).

\section{Preparation of geosmin and 2-MIB standards}

Geosmin and 2-MIB standard samples were purchased from Sigma-Aldrich and standards of $10 \mathrm{ng} / \ell, 50 \mathrm{ng} / \ell$ and $100 \mathrm{ng} / \ell$ 
were prepared since such concentrations are typical in surface water. SPME was used to extract geosmin and 2-MIB from the standards and GC-MS was utilised for the analysis of these compounds. A calibration curve was plotted in order to determine the concentration of geosmin and 2-MIB after passing the sample through the polymer.

\section{Humic acid determination}

Humic acid was purchased from Sigma-Aldrich and standards of $1 \mathrm{mg} / \ell, 2 \mathrm{mg} / \ell, 3 \mathrm{mg} / \ell, 5 \mathrm{mg} / \ell, 10 \mathrm{mg} / \ell$ and $15 \mathrm{mg} / \ell$ levels were prepared using HPLC grade water. The UV absorbance (at $254 \mathrm{~nm}$ ) measurements were carried out on a CARY-50 UV spectrophotometer. A calibration curve was plotted from which the concentration of the samples was calculated.

The synthetic water samples were also analysed on the UV to determine the concentration of the humic acid after passing the water sample through the polymer. The measurement was done at a UV absorbance wavelength of $254 \mathrm{~nm}$ (Hepplewhite et al., 2004: Mozia et al., 2005).

\section{Preparation of humic acid, geosmin and 2-MIB multi- standard}

Three different multistandard solutions of humic acid, geosmin and 2-MIB were prepared by varying the humic acid concentration while the geosmin and 2-MIB concentration was kept constant. The levels were at $5 \mathrm{mg} / \ell$ humic acid and $100 \mathrm{ng} / \ell$ for geosmin and 2-MIB, $10 \mathrm{mg} / \ell$ humic acid and $100 \mathrm{ng} / \ell$ for geosmin and 2-MIB, $15 \mathrm{mg} / \ell$ humic acid and $100 \mathrm{ng} / \ell$ for geosmin and 2-MIB.

\section{Treatment of water samples}

The synthetic standard solutions (synthetic water samples spiked with humic acid, geosmin and 2-MIB) were treated with $\beta$-CD/HMDI (a polymer produced from the reaction of $\beta$-cyclodextrin and hexamethylene diisocyanate) polymers ( $\mathrm{Li}$ and $\mathrm{Ma}, 2000)$. The adsorbents $(300 \mathrm{mg}$ ) were loaded into empty cartridges and $30 \mathrm{~m} \ell$ of the synthetic water sample was passed through the polymers at a filtration rate of $10 \mathrm{~m} \ell / \mathrm{min}$. Filtration was further enhanced by the use of a vacuum pump or water aspirator. The polymer treated water samples were then extracted using SPME before injection into the GC injector port. The filtrate was analysed using the GC-MS to determine the concentration of geosmin and 2-MIB portions in the treated synthetic water sample.

\section{Results and discussion}

\section{GC/MS analysis}

The effect of the presence of humic acid, on the adsorption of geosmin and 2-MIB was studied using synthetic water samples spiked with humic acid, geosmin and 2-MIB, which were treated with CD polymers. Figures 1 and 2 show GC/MS chromatograms of the spiked water samples before and after treatment with $\beta$-CD/HMDI. It should be noted that while GC/MS was used solely for the analysis of geosmin and 2-MIB and not humic acid, some components of humic acid are detected by this technique. Peaks at retention times 10.3 and $14.1 \mathrm{~min}$, for example, were present in the humic acid standards and all samples. Geosmin and 2-MIB peaks were identifiable at retention time

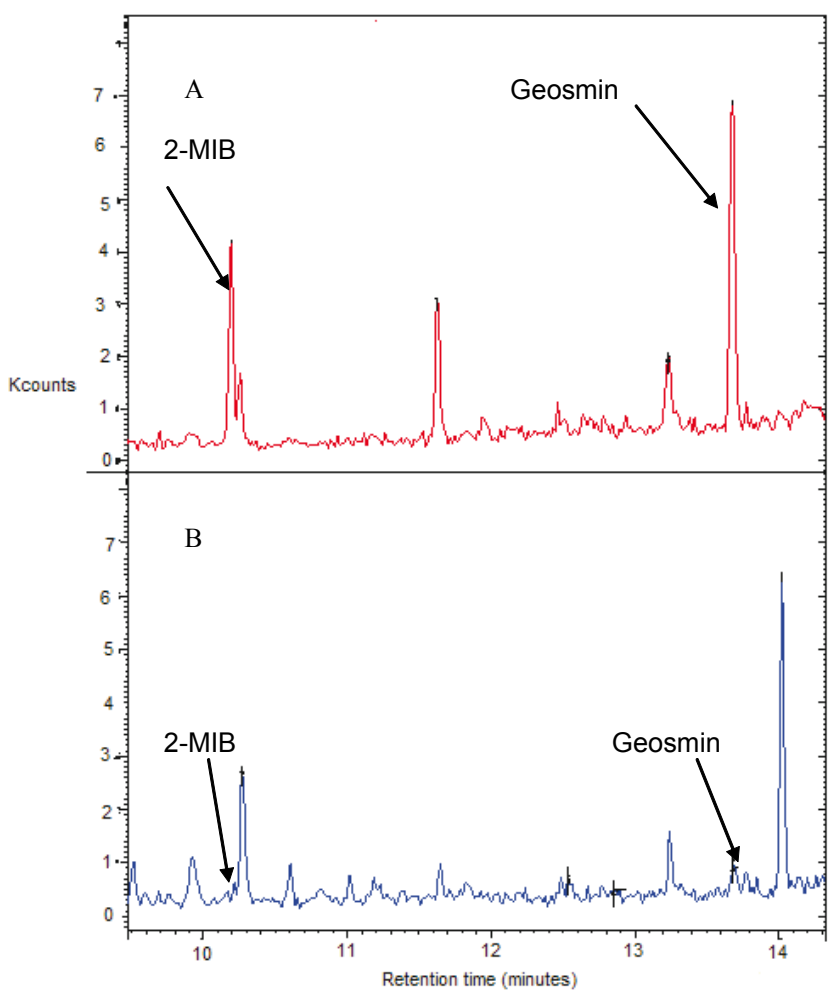

Figure 1

GC/MS chromatogram of $5 \mathrm{mg} / \mathrm{l}$ humic acid and $100 \mathrm{ng} / \mathrm{l}$ geosmin and 2-MIB before $(A)$ and after passing through $\beta-C D / H M D I(B)$

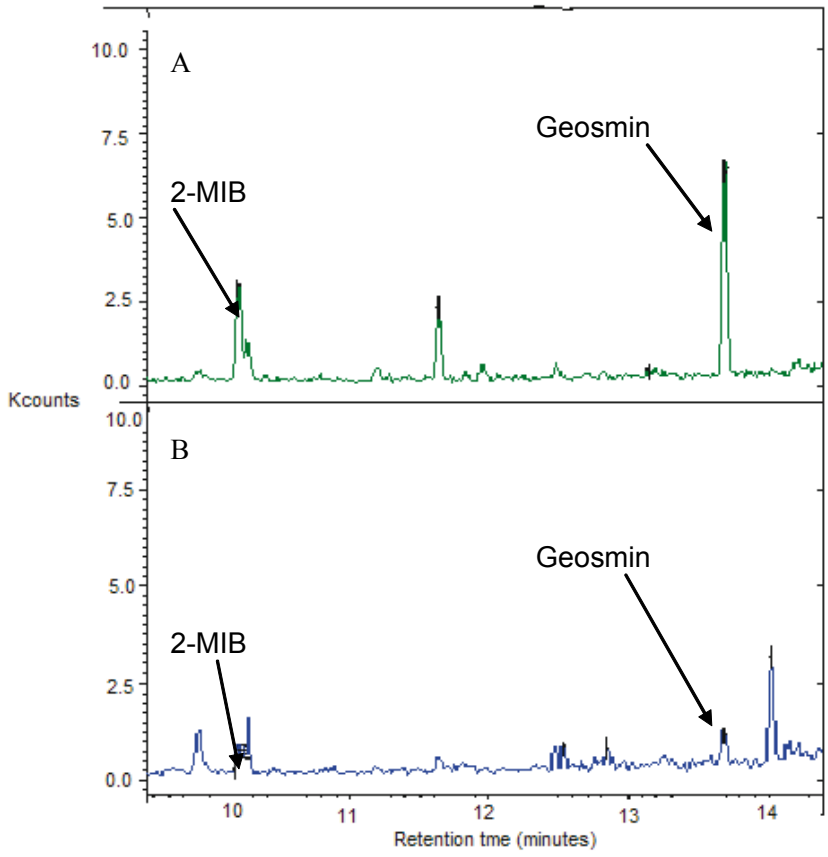

Figure 2

GC/MS chromatogram of $15 \mathrm{mg} / \mathrm{l}$ humic acid and $100 \mathrm{ng} / \mathrm{l}$ geosmin and 2-MIB before $(A)$ and after passing through $\beta-C D / H M D I(B)$

of $13.6 \mathrm{~min}$ and $10.2 \mathrm{~min}$, respectively and confirmed by both the NIST search, and comparison of the fragmentation patterns (Mamba et al., 2007). Treatment of the water samples spiked with humic acid, geosmin and 2-MIB showed that the polymers adsorbed up to less than LOQ, therefore basically $90 \%$ based on 
TABLE 1

Percentage adsorption of humic acid after passing through $\beta$-CD/HMDI

\begin{tabular}{|c|c|c|c|}
\hline Sample type & $\begin{array}{l}\text { Initial concentration } \\
\text { of humic acid (mg/le) }\end{array}$ & $\begin{array}{l}\text { Final concentration } \\
\text { of humic acid }(\mathrm{mg} / \mathrm{l})\end{array}$ & $\%$ absorbed \\
\hline $5 \mathrm{mg} / \ell$ humic acid $+100 \mathrm{ng} / \ell$ geosmin and 2-MIB & 5 & $4.85 \pm 0.015 *$ & 3 \\
\hline $10 \mathrm{mg} / \ell$ humic acid $+100 \mathrm{ng} / \ell$ geosmin and 2-MIB & 10 & $9.12 \pm 0.003 *$ & 9 \\
\hline $15 \mathrm{mg} / \ell$ humic acid $+100 \mathrm{ng} / \ell$ geosmin and $2-\mathrm{MIB}$ & 15 & $12.01 \pm 0.007 *$ & 20 \\
\hline
\end{tabular}

* Standard deviation was calculated from triplicate experimental runs.

ion counts, despite the increase in the humic acid concentration (Figs. 1B and 2B).

The high percentage adsorption of geosmin and 2-MIB onto the polymers, demonstrates that humic acid did not compete for adsorption sites on the polymers. This is further confirmed by the fact that the humic-acid fragments that are not well adsorbed continue to be detected by GC/MS and UV-Vis spectroscopy. In contrast, Newcombe et al. (2002) found that site competition seemed to be the main factor affecting the adsorption of geosmin and 2-MIB by activated carbon in the presence of NOM. In that study it was suggested that smaller NOM compounds were mostly adsorbed as they participated in direct competition with 2-MIB for adsorption sites on activated carbon. This competition between 2-MIB and certain components of NOM was confirmed in a separate study (Hepplewhite et al., 2004).

In our study, since the GC/MS analysis showed that geosmin and 2-MIB are efficiently adsorbed by the polymers without any interference from the humic acid, it was imperative that UV analysis be conducted before and after passage of water samples through the polymers in order to ascertain whether the humic acids had been adsorbed by the polymer.

\section{UV-VIS spectroscopy analysis}

The analyses in this study were completed in triplicate. The percentage humic acid removed by the polymers, together with the associated standard deviations are reported in Table 1.

UV-VIS analyses in Table 1 show that the polymers did not remove humic acid ahead of geosmin and 2-MIB. Humic acid concentration levels before and after treatment with the cyclodextrin polymers remained unchanged. This suggests that the odorous compounds being smaller in size compared to humic acids were most efficiently removed by the $\mathrm{CD}$ polymer - the cavity size of the CD ring probably accounting for such selectivity since the volume of the CD cavity is too small to fit the humic acid. In activated carbon the pores are large at the opening and generally taper internally so some geosmin can be removed if it reaches the pores first. It has been suggested by Newcombe et al. (2004) that 2-MIB could reach the adsorption sites before pore blockage by larger compounds such as humic acids.

Noteworthy is the fact that the results obtained in this research further confirm our earlier observations that the water-insoluble $\mathrm{CD}$ polymers are best suited for the removal of small (molecular) organic pollutants (e.g. trichloroethylene, nitrophenol and chlorinated benzene) from water than bigger organic compounds such as humic acids. While activated carbon would still remove humic acids during water treatment, CD polymers would ideally be positioned after activated carbon in the water treatment train. The prospect of using the cyclodextrin polyurethane in a pilot water treatment plant is currently being pursued.

\section{Conclusion}

Geosmin and 2-MIB were adsorbed efficiently by the cyclodextrin polyurethane polymers despite the presence of humic acids. This could be attributed to the difference in the sizes of the organic compounds - humic acids being larger than geosmin and 2-MIB. Humic acid is a good model of NOM in the water system and unlike activated carbon; humic acid does not block the sites of the cyclodextrin polymers. Practically, the findings in this study suggest that these polymers would be suited for the penultimate stages of the water treatment train after ozonation, UV and activated carbon filtration for the removal of NOM. The CD polymers, in the latter stages, would then adsorb microorganic pollutants that would not have been removed in the earlier stages of water treatment.

\section{Acknowledgements}

The authors wish to acknowledge with gratitude funding for this project obtained from Water Research Commission, National Research Foundation (NRF), University of Johannesburg and Eskom's Tertiary Support Programme (TESP).

\section{References}

DE WUILLOUD JC, WUILLOUD RG, SADI BB and CARUSO JA (2003) Trace humic and fulvic acid determination in natural water by cloud point extraction/pre-concentration using non-ionic and cationic surfactants with FI-UV detection. The Analyst 128 (5) 453-458.

HEPPLEWHITE C, NEWCOMBE G and KNAPPE DRU (2004) NOM and MIB, who wins in the competition for activated carbon adsorption sites? Water Sci. Technol. 49 (9) 257-267.

LI YH, LEE CW and GULLET BK (2002) The effect of activated carbon surface moisture on low temperature mercury adsorption. Carbon 40 (1) 65-72.

LI D and MA M (2000) Nanosponges for water purification. Clean Prod. Process. 2 (2) 112-116.

MAMBA BB, KRAUSE RW, MALEFETSE RW, MHLANGA SD, SITHOLE SP, SALIPIRA KL and NXUMALO EN (2007) Removal of geosmin and 2-methylisoborneol (2-MIB) in water from Zuikerbosch Treatment Plant (Rand Water) using $\beta$-cyclodextrin polyurethanes. Water SA 33 (2) 223-227. http://www.wrc.org.za/downloads/watersa/2007/Apr\%2007/2002.pdf

MHLANGA SD, MAMBA BB, KRAUSE RW and MALEFETSE TJ (2007) Removal of organic contaminants from water using nanosponges cyclodextrin polyurethanes. J. Chem. Technol. Biotechnol. 82 (4) 382-388.

MOZIA S, TOMASZEWSKA M and MORAWSKI AW (2005) Studies on the effect of humic acids and phenol on adsorption-ultrafiltration process performance. Water Res. 39 (2-3) 501-509.

NEWCOMBE G, MORRISON J, HEPPLEWHITE C and KNAPPE DRU (2002) Simultaneous adsorption of MIB and NOM onto activated carbon.II. Competitive effects. Carbon 40 (12) 2147-2156.

NAKAMURA S and DAISHIMA S (2005) Simultaneous detection of 22 volatile organic compounds, methyl-tertbutyl ether, 1,4-dioxane, 
2-methylisoborneol and geosmin in water by headspace solid phase microextraction-gas chromatography-mass spectrometry. Anal. Chim. Acta 548 (1-2) 79-85.

QUINLIVAN PA, LI L, and KNAPPE DRU (2005) Effects of activated carbon characteristics on the simultaneous absorption of aqueous organic micropollutants and natural organic matter. Water Res. 39 (8) $1663-1673$.

TENNANT MF (2004) Activation and Use of Powdered Activated Carbon for Removing 2-Methylisoborneol in Water Utilities. Ph.D. Thesis, The Graduate School of the University of Florida, Florida, United States of America. 